\title{
Una experiencia de co-docencia en la universidad basada en la producción de visualidades colectivas.
}

\author{
FERNANDO MIRANDA \\ NATALIA GRAS \\ YOHNATTAN MIGNOT
}

Fernando Miranda es Doctor en Bellas Artes con orientación en Educación Artística (Facultad de Bellas Artes - Universidad de Barcelona) y Licenciado en Ciencias de la Educación (Facultad de Humanidades y Ciencias de la Educación-Universidad de la República, Uruguay. Profesor Titular del Instituto "Escuela Nacional de Bellas Artes" (asimilado a Facultad) de la Universidad de la República. Investigador Nivel I, Sistema Nacional de Investigadores, Agencia Nacional de Investigación e Innovación (ANII) - Uruguay. Responsable desde 2005 del Núcleo de Investigación en Cultura Visual, Educación y Construcción de Identidad de la UDELAR con el que ha desarrollado proyectos a nivel nacional e internacional.

Afiliação: Universidad de la Republica Uruguay

Orcid: https://orcid.org/0000-0003-0519-0918

Natalia Gras es Doctora en Ciencias Sociales, Universidad Autónoma Metropolitana, México; Magíster en Economía y Gestión de la Innovación, Universidad Autónoma Metropolitana, México y Licenciada en Economía por la Facultad de Ciencias Económicas y de Administración de la Universidad de la República, Uruguay. Profesora adjunta de la Unidad Académica de la Comisión Sectorial de Investigación Científica de la Universidad de la República. Es miembro del Sistema Nacional de Investigadores de Uruguay y forma parte de las redes GLOBELICS (Global Network for Economics of Learning, Innovation, and Competence Building Systems) y LALICS (Latin American Network for Economics of Learning, Innovation, and Competence Building Systems).

Afiliação: Universidad de la Republica Uruguay

Orcid: https://orcid.org/0000-0002-2653-8314

Yohnattan Mignot es doctorando en Investigación en Arte Contemporáneo, Universidad del País Vasco (UPV/EHU); Máster en Investigación y Creación en Arte, Universidad del País Vasco (UPV/EHU), España; Licenciado en Artes Fotografía, Universidad de la República, Uruguay. Docente Ayudante en el Área de Foto-Cine-Video del Instituto Escuela Nacional de Bellas Artes, Universidad de la República. Integrante del Núcleo de Investigación en Cultura Visual, Educación y Construcción de Identidad desde 2017. Ha realizado diversas exposiciones artísticas individuales, nacionales e internacionales: Intrusos (Festival LAN, Bilbao, España. 2020) Ensayos sobre el Trabajo (Bienalsur. Rosario, Argentina. 2019), Terrain Vague (Alianza Francesa. Montevideo, Uruguay. 2017). Ha obtenido el primer premio del Certamen de Arte ElA21 (País Vasco, España. 2020).

Afiliação: Universidad de la Republica Uruguay

Orcid: https://orcid.org/0000-0002-2413-7146 


\section{- RESUMEN}

El artículo trata sobre una experiencia de co-docencia universitaria, con profesores y profesoras estudiantes de posgrado. Se fundamenta en el trabajo interdisciplinario, desde una aproximación a la investigación basada en las artes y a partir de la producción de visualidades colectivas sobre las representaciones que los docentes tienen de su trabajo, su formación y los entornos institucionales en que se desempeñan, concebidos como sistemas. La utilización de la fotografía es el medio de producción visual elegido para generar un conjunto de imágenes que actúan como evidencias de los resultados del análisis, la descripción y la crítica, que los docentes realizan de sus prácticas.

\section{- PALABRAS CLAVE}

Co-docencia, visualidades colectivas, fotografía, investigación basada en las artes, sistemas.

\section{- RESUMO}

O artigo trata de uma experiência de co-docência universitária, com professores e professoras estudantes de pós-graduação. Ela se baseia em um trabalho interdisciplinar, de uma abordagem à pesquisa baseada nas artes e da produção de visualidades coletivas sobre as representações que os professores têm de seu trabalho, sua formação e os ambientes institucionais nos quais atuam, concebidos como sistemas. O uso da fotografia é o meio de produção visual escolhido para gerar um conjunto de imagens que funcionam como evidência dos resultados da análise, descrição e crítica que os professores fazem de suas práticas.

\section{PALAVRAS-CHAVE}

Co-docência, visualidades coletivas, fotografia, investigação baseada nas artes, sistemas. 


\section{Introducción}

Las experiencias de co-docencia, desde una perspectiva interdisciplinaria, no son comunes en las universidades.

Desarrollamos una propuesta con profesores y profesoras, a la vez estudiantes de posgrado de la asignatura Pedagogías Culturales, que incorporó, como eje estructurante, la producción de visualidades colectivas sobre las representaciones de los modelos docentes en la educación superior.

La experimentación en distintas maneras de representar en imágenes los sistemas de trabajo y los entornos institucionales encontraron en la utilización de la fotografía el medio propicio para evidenciar resultados.

La propuesta se aproxima a los preceptos teóricos y prácticos de la investigación basada en las artes, y en sus posibilidades para el uso creativo.

\section{Caracterización del curso de Pedagogías Culturales: profesores como alumnos}

El curso de Pedagogías Culturales se desarrolla en el marco del programa de Maestría en Enseñanza Universitaria de la Universidad de la República en Montevideo.

Se trata de un programa público de formación al que concurren profesores y profesoras de las más diversas disciplinas de la universidad y de la formación de enseñanza secundaria o magisterio.

Se mezclan así docentes de universidad, con origen en disciplinas sociales y humanísticas, con los que vienen de una formación científica dura y experimental, hay quien llega del Diseño y quien lo hace de la tradición de la docencia en educación.

En la edición de 2019-2020, un total de diez estudiantes culminaron el proceso de formación de la asignatura, cuyo objetivo principal es contribuir a la formación docente universitaria desde las aportaciones de la Pedagogía y sus relaciones con las formas de producción cultural contemporánea.

Para el cumplimiento de este objetivo nos basamos en distintas prácticas basadas en las artes, dentro de las que enfatizamos la producción visual y la creación colaborativa de imágenes, pequeñas acciones performáticas y producción de textos autobiográficos que llegan a veces a tonos literarios.

Las propuestas de trabajo se orientaron en torno a conceptualizar y narrar trayectorias y modelos, a representar mediante el dibujo, la fotografía y diversos objetos materiales los modelos de enseñanza que se construyen en nuestras instituciones de educación superior.

La modelización gráfica tuvo procesos de distintas etapas y versiones para llegar a un resultado en que cada grupo se sintiera identificado.

\section{El curso de Pedagogías Culturales y la investigación basada en las artes}

A efectos de abordar este trabajo lo hemos hecho desde una perspectiva próxima a la investigación basada en las artes en el sentido en que lo plantean Fernando Hernández (2008), Natalia Calderón (2015) y ambos (2019), como la 
producción de un conocimiento disruptivo en la universidad.

Las prácticas de investigación, en este caso en una entorno de formación universitario, tienen que recoger las ideas, los puntos de vista, la experiencia y la expresión subjetiva de quienes participan.

Desde esta convicción nos interesa la perspectiva de la investigación basada en las artes en cuanto relato y descubrimiento "como parte de un proceso que no se centra en una subjetividad que se proyecta en sí misma, sino en la relación con los otros o con la experiencia sobre la que se indaga de manera compartida" (HERNÁNDEZ; FENDLER, 2014, p. 5).

La posibilidad de producir conocimiento acerca de las prácticas educativas en las aulas de la universidad, en perspectiva del propio contenido que nos agrupa - y cuando se trabaja con profesores y profesoras de distintas disciplinas y muy diversa formación - , necesita de dispositivos comunes que permitan zonas de contacto, de representación y de generación de visualidades.

Un dispositivo de trabajo es, según hemos señalado en un texto anterior (XX; YY; ZZ; 2016, p. 13) "un artificio estructural y organizativo consciente, creado para la producción y la acción colectiva".

Así, cuando proponemos a quienes participan la producción de visualidades en procesos grupales, como forma de narrar la experiencia de la docencia universitaria, involucramos la posibilidad de la irrupción de las subjetividades no como una expresión individual, sino como una construcción necesariamente colectiva.

En términos de la importancia de la condición narrativa, y su relación con la construcción colectiva, las subjetividades tienen que ver con espacios y relatos compartidos, donde la historia se produce necesariamente en relación (HERNÁNDEZ; FENDLER, 2014).

Tomar la producción visual de los participantes a partir de las experiencias de trabajo colaborativo no supone ni la fascinación por la forma, ni la estetización que adorna una instancia de formación, sino dar la posibilidad de que allí residan los resultados propios de las narrativas colectivas.

La incorporación de materiales, tecnologías y maneras proyectuales de creación colectiva remite a las artes pero no para generar la ilusión de la expresión individual, sino para aproximarnos de otra manera al conocimiento que tiene que ver, en este caso, con los espacios de formación universitaria y las vidas de los y las docentes en ellos.

Como refiere Hernández (2013):

Cuando narramos y documentamos no lo hacemos como parte de un ejercicio celebratorio sino como una forma de ponernos en tensión y salir de nuestra zona de confort. Permitiendo que los otros entren en una red que no se acaba en nuestro grupo-clase, en un proyecto artístico, en la intervención en un museo, o en la investigación que realizamos junto a los jóvenes. Lo que pretendemos es extender a otros, generar formas de compartir que posibiliten nuevas complicidades y relaciones (p. 88). 
Lo que allí se produce no ilustra un conocimiento, sino que es el conocimiento en una forma que busca desarmar la condición hegemónica marcada por las pretensiones de exterioridad, objetividad y dualidad en que se lo concibe habitualmente.

Es decir: a) el conocimiento no es extraño a los sujetos, no está fuera esperando ser revelado, sino que éstos participan activamente de su producción involucrados en los juegos de relaciones - sociales, lingüísticas, políticas, entre otras - que participan de esa producción; b) el conocimiento involucra el poder y sus conflictos evidenciados en jerarquías, omisiones, relevancias; y c) el sujeto que conoce y el objeto conocido no son independientes, no hay intuición, inspiración o esencia que resida en la subjetividad por fuera de la trama de relaciones en que participa quien conoce.

Así, y contrariando la lógica instalada en la tradición moderna de las artes, se cuestiona el concepto mismo de autoría por la acción evidente del colectivo como marco y posibilidad de creación. Ubicamos la condición de autoría en la posibilidad de la realización subjetiva en y con el grupo.

Si participamos a los docentes de espacios de formación en que puedan conectar lo subjetivo con una experiencia visual en forma integral y productiva, damos paso a capacidades de producción de conocimiento no realizable de otras maneras. A veces porque el conocimiento opera tácitamente, y "se trataría de tener en cuenta ciertos procesos cognitivos y/o comportamientos que son sustentados por medio de operaciones inaccesibles a la conciencia" (EVHAVARRÍA, 2011, p. 5), otras veces porque la construcción colectiva del conocimiento, mediante acciones basadas en las artes, amplía y hace más densa la experiencia vital, agregando capas de miradas y perspectivas.

Sin perjuicio de que la condición política y reflexiva del llamado "conocimiento tácito" es objeto de discusión - ya desarrollado por Natalia Calderón (2015) -, no nos referimos aquí a una suerte de sinonimia del término con lo que podríamos denominar "sentido común", como a veces parece tomarse el concepto.

Por el contrario, vemos la posibilidad de traer al frente y combinar visualidades y acciones performáticas $-\mathrm{y}$, por tanto, hacer explícitos, reconocibles y situados - ciertos conocimientos, como si se tratase de una operación de un programa informático de edición de imágenes.

Un curso centrado en las pedagogías culturales, junto a profesores y profesoras de universidad, da el espacio para recuperar las historias personales como relatos de tránsito por la institucionalidad educativa, produciendo unas maneras de colaboración que favorezca la construcción identitaria de lo que nos corresponde individualmente pero también de lo que somos en común y de lo que nos diferencia.

Como señala García-Huidobro (2013) respecto de su investigación con mujeres artistas docentes,

[...] acercarme a conocer en profundidad sus historias y cómo sus diversas experiencias sociales, políticas y personales las llevan a comprender y enfrentar sus prácticas artísticas y docentes como mujeres, nos permitirá comprender en conjunto, de qué manera lo 
individual dialoga con lo social y pone en juego la conformación de sus identidades. (p. 29)

\section{Una experiencia de docencia compartida.}

Esta intervención en el curso de Pedagogías Culturales tiene que ver con una experiencia de co-docencia (co-teaching) entre tres docentes provenientes de distintos campos de formación disciplinar: Artes Visuales y Fotografía, Educación, Economía.

La co-docencia, de acuerdo a las posturas más recibidas, incorpora dos o más profesores y profesoras de similares o diferentes niveles de formación, experiencia o procedencia disciplinar que actúan en una misma área de contenidos programáticas, en este caso el proceso del curso planteado.

Esto permite trabajar juntos, discutir objetivos, finalidades y sentido de la formación respecto a lo que se comparte en el aula. (LOCK et al, 2016; HOWLETT; NGUYEN, 2020)

Si bien la co-docencia surge en los años '60 en entornos de modalidades de educación inclusiva, de forma que al docente especialista en los contenidos se incorporara un segundo profesional de la educación que colaborara en las necesidades particulares de los estudiantes, la idea de compartir la enseñanza fue extendiéndose a todos los niveles de enseñanza y más allá de situaciones especiales.

De las distintas modalidades posibles y más aceptadas, varias ocurren en el ámbito de la formación artística. Así podemos ver la existencia de un docente a cargo y un co-docente observador y/o asistente, el trabajo en equipo de profesores o en espacios paralelos.

Incluso en aquellas áreas del Diseño o la Arquitectura que implican las llamadas metodologías proyectuales, la co-docencia admite formas de trabajo en estaciones o equipos de estudiantes simultáneos con docentes trabajando colectivamente.

En los hechos, los profesores y las profesoras universitarias están habituados a colaborar y participar conjuntamente de procesos de investigación, cooperan en la realización de proyectos de pesquisa, pero difícilmente colaboren en términos de co-docencia. Esto requiere procesos de confianza también para los estudiantes, no habituados a estas prácticas de enseñanza (LOCK et al., 2016).

La discusión teórica posibilita hacer explícitas las contradicciones entre las experiencias de los distintos profesores involucrados en el trabajo; también negociar contenidos, maneras de trabajo, experiencias, y promover el crecimiento común (FERGUSON; WILSON, 2011).

Es así que las autoras entienden que este tipo de experiencias favorece la construcción de grupos docentes más fuertes tanto a nivel del personal en formación como de los docentes más experimentados.

Sin perjuicio de esto, la experiencia indicaría que un conocimiento previo de los y las co-docentes, e incluso relaciones de compañerismo o amistad previa, genera niveles de confianza relevantes al momento del ejercicio en el aula universitaria. 
En nuestro caso, además, la experiencia de co-docencia del equipo se constituye en sí misma en un ejemplo de trabajo para las profesoras y los profesores en formación, todos con una experiencia en vías de consolidación en la educación superior. La modalidad de compartir la docencia universitaria, permitió que los participantes se vieran "en espejo" con la alternativa desarrollada, alcanzando en el ejemplo la posibilidad de poner en contraste sus propias prácticas y experiencias.

Esta oportunidad de contrastar la trayectoria y decisiones propias con las del equipo docente, facilita intercambiar desde la reflexión personal las decisiones de "resolución" de los ejercicios de creación propuestos, al tiempo que desafía a la negociación entre los integrantes de los sub-grupos de trabajo en que se organizó la clase.

Trabajos recientes (MORELOCK et al., 2017) afirman los beneficios evidentes para quienes participan de experiencias de co-docencia, quienes consideran que mejoran sus experiencias de enseñanza si combinan con sus saberes y experiencias con sus colegas, favoreciendo en consecuencia los procesos de aprendizaje de sus estudiantes.

En sentido convergente, Hernández \& Padilla-Petry afirman que en el caso de la

[...] co-docencia, hemos comprobado que esta paradoja, al tiempo que diluye posiciones y difumina roles establecidos entre los docentes, afecta a los estudiantes, pues quiebra y cuestiona una posición asumida a lo largo de años de normalizada posición subalterna que los suele llevar a renunciar a su responsabilidad de ser" $(2019,23)$.

Del mismo modo la co-docencia colabora en la ruptura de una educación basada en disciplinas, especialmente cuando se trata de la universidad del siglo XX y lo que va del XXI (ASHBY; EXTER, 2019), ubicando la centralidad consecuente en materias aisladas y conceptos que responden a lógicas y paradigmas de aquellas.

Esta inerdisciplinariedad, aunque es una novedad del abordaje de la investigación y la enseñanza universitarias va en el sentido del concepto de aprendizaje integrador - integrative learning - lo que colabora en que los planes de estudios tengan sentido para los estudiantes (ASHBY; EXTER, 2019), en este caso de posgrado.

En nuestra experiencia, la oportunidad de un acción de docencia basada en las artes, en nuestro caso, ha sido útil no sólo para discutir nuestros marcos y referencias como docentes, sino también fomentar el diálogo de disciplinas de nuestros alumnos-docentes.

\section{Marcas en los libros: cómo estudian los que enseñan}

Una de las acciones que desarrollamos tiene que ver con las evidencias de la diversidad de intenciones y formas de apropiación de los textos de estudio por parte de los estudiantes-profesores que constituyeron nuestro grupo de trabajo. 
La propuesta realizada al grupo fue sobre la selección personal de un texto que consideraran relevante para su trabajo y acción profesional como docentes. La intención era generar la comprensión, reflexión y crítica sobre las maneras de estudiar, vincularse con los textos y actuar sobre ellos, a partir de las marcas visuales e intervenciones personales.

Una vez cada participante seleccionó el texto de relevancia se registró cada imagen y se produjeron distintas visualidades vinculadas a cada estudiante, lo que dio lugar al uso de la imagen fotográfica como registro y prueba.

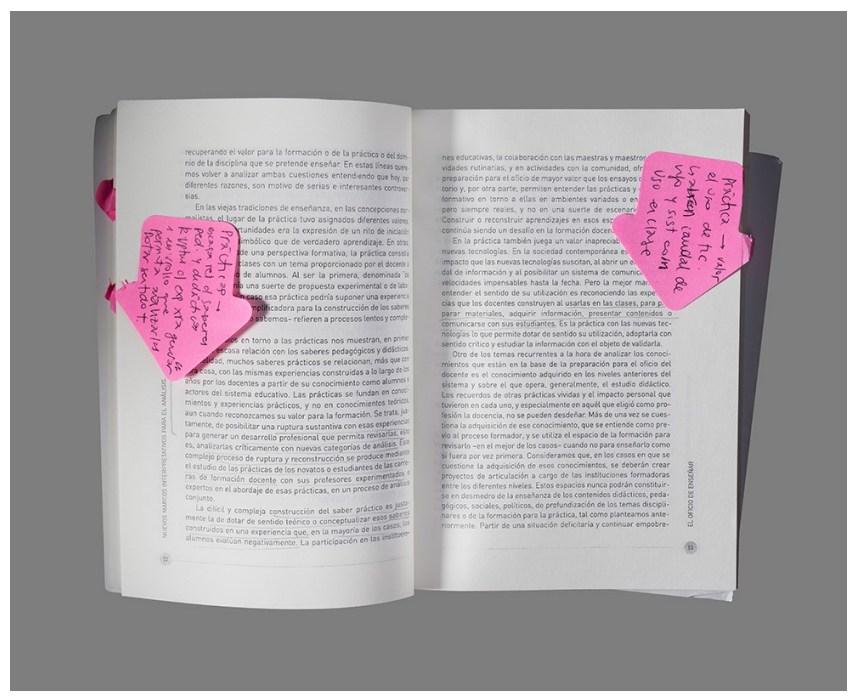

Figura 1. Ejemplo de intervención en libro de estudios de una profesora, 2019. Fotografía de los autores.

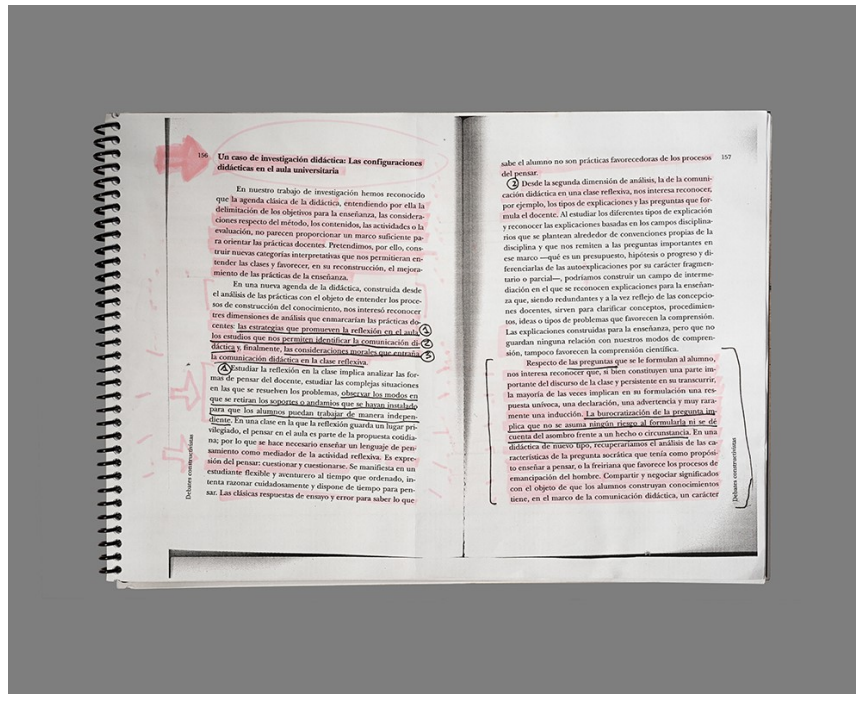

Figura 2. Ejemplo de intervención en libro de estudios de una profesora, 2019. Fotografía de los autores. 


\section{La fotografía como evidencia y su lugar en la experiencia educativa}

Un comentario filológico de los textos no serviría de nada: en los textos no se encuentra más que cuanto en ellos hemos puesto

(MERLEAU-PONTY, 1945, p. 8)

Un conjunto de libros abiertos se expone ante nosotros, al leer los contenidos que vemos en sus páginas encontramos una serie de características comunes entre ellos. Se habla de didácticas, pedagogías, profesores y maestras que nos llevan a una idea sobre un marco educativo desde la docencia.

Si situamos estos textos en el medio en que los visibilizamos dejan de ser páginas y nos colocamos ante una imagen fotográfica, lo que quizás nos sugiere un tipo de observación particular teniendo en cuenta este lenguaje visual.

¿Por qué no reescribir en un documento lo que allí se dice? ¿Por qué no recortar las páginas del libro? ¿Por qué no escuchar una voz que lea estas palabras? Entonces, ¿qué nos plantea observar estos textos dentro de una imagen producida por la fotografía?.

En este sentido podemos traer el pensamiento Marshall McLuhan (1967) cuando nos dice que "el medio es el masaje es una mirada a nuestro alrededor para ver que está pasando. Es un choquedoscopio de situaciones multifacéticas que se entretejen". (p. 10)

Si somos capaces de pensar en el medio en el que colocamos la mirada veremos más allá de lo que nosotros creemos ver, estaremos situados en este entretejido que se nos impone.

Desde este punto de vista, la fotografía nos trae mucho más que un conjunto de textos, nos hace ver el objeto libro con sus páginas abiertas, intervenidas, marcadas, con su tamaño aparente (Figs. 1 y 2), y nos introduce en un campo de visibilidad que se relaciona con el tiempo y el espacio. John Berger (2013) afirma que: "El verdadero contenido de una fotografía es invisible, porque no se deriva de una relación con la forma, sino con el tiempo." (p. 35)

Así, la fotografía hace visibles las marcas que se estampan en la hoja como la huella de una sensación producida en el lector por lo leído. Un pliegue, un post-it o un rayón sobre el papel conforman una serie de signos que anuncian materialmente las palabras, oraciones o párrafos que fueron motor de sensaciones y se hacen reconocibles como una interrupción en la homogeneidad del formato del texto. Se señala un momento trascendente en la temporalidad y el espacio físico donde se desarrolla la lectura y estas marcas son el acento que permitirán identificar en un tiempo futuro aquello que allí nos detuvo.

En esta acción donde se separa una parte de un todo, se enmarca una zona de interés que es producida no solo por lo que encierra en sí misma, sino por los sentidos que le han precedido y los que aparecerán posteriormente.

Podemos pensar como una cualidad fotográfica esta capacidad de retener instantáneamente aquello que vemos para posteriormente recurrir a su huella en el futuro. La captura corresponde solo a una parte de la totalidad de luz que hay en el espacio y encuadrar consiste en separar y aislar estos rayos para colocarlos en un campo, omitiendo todo un fuera de campo que lo influye directamente. Es esta 
cualidad permite que en los estudios fotográficos o cinematográficos se produzcan las representaciones que alimentan las ficciones de la cultura, se oculta el fuera de campo que hace posible la ilusión, pero que es inseparable de ella.

La imagen fotográfica se crea dentro del campo de visión que nos da nuestro cuerpo pero se produce fuera de él. Y este acto transforma el objeto en imagen, en este caso, se produce un doble del libro abierto, pero que ya no es el libro:

El deseo de convertirse en cosa -en este caso una imagen- es el resultado de la lucha en torno a la representación. Los sentidos y las cosas, la abstracción y la excitación, la especulación y el poder, el deseo y la materia convergen efectivamente en las imágenes. (STEYERL, 2012, p.54)

Esta lucha de la cosa y lo que evoca, de lo que se presenta y lo que se representa, entre la imagen fotográfica, el objeto fotografiado y la definición de este objeto se despliega literalmente en la obra una y tres sillas del artista Joseph Kosuth (1965) donde estas ambigüedades toman cuerpo en el espacio expositivo. Allí accedemos a un terreno inestable de relaciones en algo tan cotidiano como lo que es una silla, lo que pensamos de silla, lo que es como cosa y lo que evoca como fotografía.

En este territorio de encuentros y desencuentros, que es la imagen, podemos ver con extrañeza algo que nos es familiar. En los libros abiertos reconozco la huella de una huella dentro de un texto, veo la imagen y el gesto de algo que se señala, pero no veo las implicancias que han hecho que estas imágenes existan. Hubo un grupo de estudiantes que compartió la experiencia de este curso, estos libros convivieron en este espacio, fueron leídos y disonantes ante la diversidad de disciplinas que convivían en el momento.

Estas diferencias permitieron revisar las particularidades de cada conocimiento en tanto visión del mundo en cada uno/a y quizás algo de ello podemos deducir en la serie fotográfica, pero nunca de forma absoluta porque en cuanto el objeto obtiene su doble fotográfico, este genera sus propias realidades, en palabras de Joan Fontcuberta (1997):

\footnotetext{
La fotografía, en su origen, tuvo que acercarse a la ficción para demostrar su naturaleza artística y su objetivo propietario ha consistido en traducir los hechos en soplos de la imaginación. Hoy en cambio lo real se funde con la ficción y la fotografía puede cerrar un ciclo: devolver lo ilusorio y lo prodigioso a las armas de lo simbólico que suelen ser a la postre las verdaderas calderas donde se cuece la interpretación de nuestra experiencia, esto es, la producción de realidad. (p. 129)
}

Así, podremos ver como el tiempo degradará las páginas de los libros, pero la fotografía que hemos tomado conservará todos los detalles de un tiempo pasado que nos enfrenta a esta relación, no de forma sino de tiempo, en la que Berger nos hace pensar.

Entre pliegues, marcas, objetos y fotografía encontramos el trabajo de la artista Moyra Davey que utiliza la analogía de la huella física y la fotografía como 
huella en una serie de fotos que ella misma imprime, pliega y envía por correo postal a algún destinatario con la condición de que sean devueltas a ella por este mismo medio.

Al recuperar cada foto éstas adquieren un carácter objetual, ya que a través de los sellos postales que tiene encima y sus pliegues aún más acentuados se pone de manifiesto a modo de palimpsesto los tiempos, los espacios y las personas que han incidido en el propio material. Hay un conjunto de capas de tiempo y espacio que confunden a la fotografía con el objeto y al objeto con la fotografía.

En este sentido, el conjunto de imágenes vuelve anónimas las experiencias singulares a las que cada papel impreso ha sido sometido, pero sin embargo están allí, como las intenciones de los estudiantes que seleccionaron la página de un libro que hasta el momento de su registro fotográfico consideraban el momento más importante de todas sus lecturas, pero solo vemos el objeto libro abierto aparecerse ante nosotros, vemos algo señalado, algo para ser leído en el interior de un instante en la vida de un objeto, pero sin embargo cuando accedemos a lo que las palabras dicen, como vimos con Merlau-Ponty (1945), no se encuentra más que cuanto en ellos hemos puesto y esta ambigüedad también se produce en el encuentro con lo que vemos, que en palabras del mismo autor:

La visión se alcanza a sí misma y se reúne en la cosa vista. Le es esencial el captar y, de no hacerlo, no sería visión de nada; pero le es esencial el captarse en una especie de ambigüedad y oscuridad, porque no se posee y se escapa, por el contrario, en la cosa vista. (MERLAU-PONTY, 1945, p. 386)

\section{Sistemas como maneras de representación}

Un sistema como forma de representación puede entenderse de acuerdo con la conceptualización de "sistemas externos de representación" realizada por Pérez-Echeverría, Martí y Pozo (2014). Es decir, como un sistema de signos que haciendo referencia a cierta realidad, la significan de manera diversa según cómo sea la composición y la combinación de signos utilizados para darle sentido.

Siguiendo a esos autores, hay dos formas de dar significado a la representación: "motivada" o "arbitraria". Cada una de ellas depende de la relación que se establezca entre el signo y aquello que se quiere representar. Si las características del signo se asocian directamente con las características de lo que se quiere representar, entonces el significado o la relación entre ambas es motivada y, por lo tanto, la significación se construye según las características de lo que se quiere representar. Por el contrario, la relación entre signo y aquello que se busca representar es arbitraria, cuando no hay una correspondencia directa entre sus características y, por lo tanto, lograr sentido implica recurrir y comprender un conjunto de reglas sobre la composición y combinación de signos que -generalmente- se derivan de convenciones. A modo de ejemplo: la matemática puede categorizarse como un sistema externo de representación arbitrario ya que, dependiendo de la combinación de los signos y sus reglas de composición, son capaces de producir sentido o, dicho de otro modo, de representar y significar conceptos, sus relaciones, teorías, etc. 
A la vez, otra dimensión relevante de los sistemas externos de representación se vincula con lo que representan, con el contenido de la representación (PÉREZ-ECHEVERRÍA; MARTí; POZO, 2014). Si bien cada sistema se desarrolla asociado a cierto espacio conceptual y las restricciones conceptuales de ese espacio inciden en la manera que ese sistema representa; eso no significa que la relación sea exclusivamente unidireccional, desde lo conceptual a lo que se busca representar. Por el contrario, se trata de una relación bi-direccional, donde lo conceptual y lo representacional se transforman y re-definen mutuamente. Además, un sistema determinado puede utilizarse para representar un contenido distinto de su atribución conceptual original -por ejemplo: el número de puerta de una casa, utiliza propiedades numéricas, pero no para representar la cantidad de casas, sino para identificar/representar una ubicación específica-.

Además de lo indicado en el párrafo anterior sobre qué representa un sistema determinado, importa también saber cómo representa (PÉREZECHEVERRÍA; MARTÍ; POZO, 2014). Para avanzar en una respuesta y siguiendo a esos autores, una representación no es una copia de lo que se busca representar, sino que exige un proceso de aprendizaje asociado a la traducción/abstracción que supone la aplicación de ciertas reglas composición y transformaciones. Es decir, el aprendizaje de sistemas de representación -en tanto es visual y gráfico- implica, por un lado, tener en consideración la ubicación espacial de sus objetos/signos/componentes $y$, por otro lado, desarrollar un proceso de explicitación de las relaciones entre esos componentes; al tiempo que requiere del dominio de otros sub-sistemas de representación y tener la capacidad de combinarlos dando sentido y transformándolos. A la vez, un sistema específico de representación externa de la realidad debe seguir un conjunto de restricciones que también hay que aprender para poder entender y crear nuevos significados.

Adicionalmente, no todos los sistemas externos de representación se aprenden de igual forma. Los procesos de aprendizaje de distintos sistemas de representación dependerán tanto de las características específicas de los sistemas como de las de quienes aprenden, sus experiencias, sus conocimientos generales y específicos sobre lo que buscan representar y sobre diversos sistemas de representación, sus objetivos, metas, etc. (PÉREZ-ECHEVERRÍA; MARTí; POZO, 2014).

En el marco del curso Pedagogías Culturales, se desarrollaron diversas prácticas orientadas al uso y la construcción de dos sistemas externos de representación arbitraria, vinculados tanto a la construcción individual de un texto autobiográfico como a la creación colectiva de una representación visual. La propuesta pedagógica de desarrollo de esos dos sistemas buscaba, en el primer caso, que las personas participantes del curso pudieran representar las y los docentes que actualmente son y, en el segundo -de carácter colectivo-, sus prácticas docentes contextualizadas en un espacio pedagógico específico.

En el caso de la producción del texto autobiográfico, la intención fue que a través del uso del sistema externo de representación -escrito- las y los participantes pudieran construir una representación autobiográfica de su trayectoria docente que permitiera conocer, reflexionar, comprender y explicitar los elementos que sirven para explicar y, por lo tanto, significar las y los docentes que actualmente son, así 
como los elementos contextuales que condicionaron y condicionan dichas trayectorias. La consigna solicitaba que la autobiografía debía contener las decisiones tomadas, las circunstancias atravesadas, los deseos, los problemas enfrentados, las casualidades, las búsquedas realizadas y las decisiones tomadas que se asocian con las personas que actualmente son como docentes y, además, que diera cuenta de la construcción de su interés pedagógico.

Esta consigna implicó que para construir dicho sistema fue necesario no solamente recurrir a la escritura -en tanto sistema- sino también a otros sistemas de representación y creación de sentido que facilitaran el ordenamiento y el sentido lógico de los componentes que ese escrito autobiográfico debía incluir. Dicho de otro modo, era necesario por un lado considerar la temporalidad de los eventos -noción presente en sistemas cognitivos tales como la estadística, la historia, entre otros- que conforman la autobiografía a efectos crear sentido en términos de trayectoria docente, misma que se había construido a través de un cierto ordenamiento que relaciona los componentes de la autobiografía de una forma coherente y estructurada -noción presente en la teoría de sistemas, en el campo de las matemáticas y el modelado estructural, entre otros campos del conocimiento o sistemas cognitivos-. Además, de recurrir a los conocimientos propios sobre el contenido de esa representación.

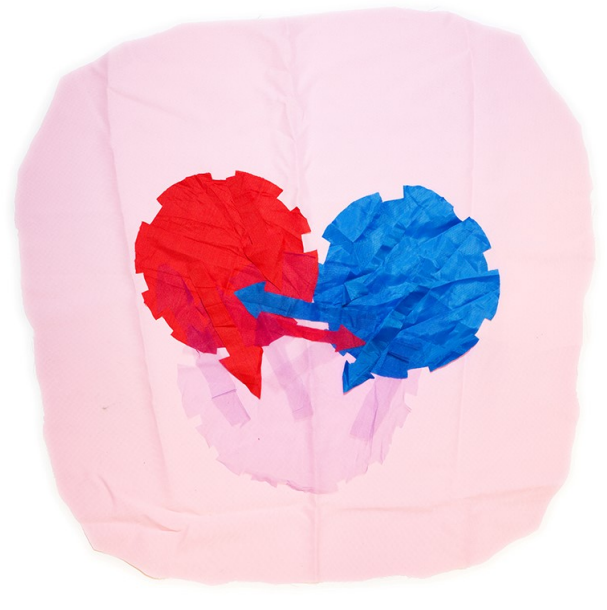

Figura 3. Representación con telas de relaciones docente - alumno - institución en un sistema de educación superior, 2019. Fotografía de los autores.

En el caso de la producción de la representación colectiva de las prácticas docentes contextualizadas, la propuesta pedagógica buscaba que a través del uso de un sistema externo de representación -gráfico y tridimensional- quienes 
participaron del curso pudieran crear y documentar un modelo colectivo de representación visual de sus respectivas prácticas docentes contextualizadas en una relación pedagógica específica del ámbito educativo terciario/universitario desde una perspectiva integrada, holística y sistémica. Adicionalmente, se proponía la elaboración de un texto que, fundado en la bibliografía trabajada en el curso, contribuyera -junto con la representación visual- a la creación de sentido, permitiendo la reflexión, el conocimiento y la explicitación de los aspectos más significativos para explicar la práctica docente situada que desempeñan. Nuevamente aquí, la combinación y re-significación de distintos sistemas de representación y conocimientos tuvieron que ponerse en juego para la construcción de dicha representación visual (Fig. 3)

La construcción de ambos sistemas externos de representación tuvo lugar a través de un proceso de aprendizaje interactivo, progresivo e incremental, en el que mediante diversas tareas las y los participantes del curso fueron explicitando los aspectos más relevantes de su trayectoria y práctica docente actual y contextualizada.

La discusión colectiva de los textos recomendados en la bibliografía del curso y de material audiovisual compartido, sirvió para la identificación de las categorías conceptuales relevantes y las diversas posibilidades para explicitar, documentar y representar visualmente las autobiografías y prácticas docentes contextualizadas.

La exposición teórica e intercambio sobre cómo construir modelos de representación gráfica y sus reglas, de acuerdo con los objetivos que se plantea o lo que se desea representar, permitió la identificación y explicitación de sus componentes centrales -los que explican resultados- y contextuales -los que los condicionan-, el tipo de relaciones (directas, indirectas, unidireccionales y/o bidireccionales) entre ellos, los signos/símbolos, su ubicación en el espacio y, como todo eso, conjuntamente y desde una perspectiva holística y sistémica, proveen sentido y crean nuevos significados.

Los ejercicios colectivos sobre narrativas, representación visual y de composición basados en distintos dispositivos pedagógicos permitieron poner en práctica paso a paso la reflexión teórica derivada de cada encuentro entre quienes participamos del curso y alcanzar como resultados finales del proceso, la construcción de los dos sistemas externos de representación mencionados.

Entre los dispositivos pedagógicos implementados en el curso están: i) el desarrollo de un trabajo en grupo de composición de narrativas con base en textos resaltados de y por cada participante del grupo; ii) exposición oral e individual al resto de participantes del curso sobre sus biografías con base en fotografías personales asociadas a sus carreras docentes; iii) la representación visual bidimensional sistémica de las trayectorias y prácticas de las y los docentes integrantes del grupo en un espacio de relación pedagógica con base en el dibujo, el color y la forma; y, iv) la representación visual tridimensional sistémica de las trayectorias y prácticas docentes situadas con base en el uso de distintos materiales -papel de diario, telas de diferentes texturas y colores, maderitas de un solo color pero de distintas formas y legos pequeños- (Fig. 4). 


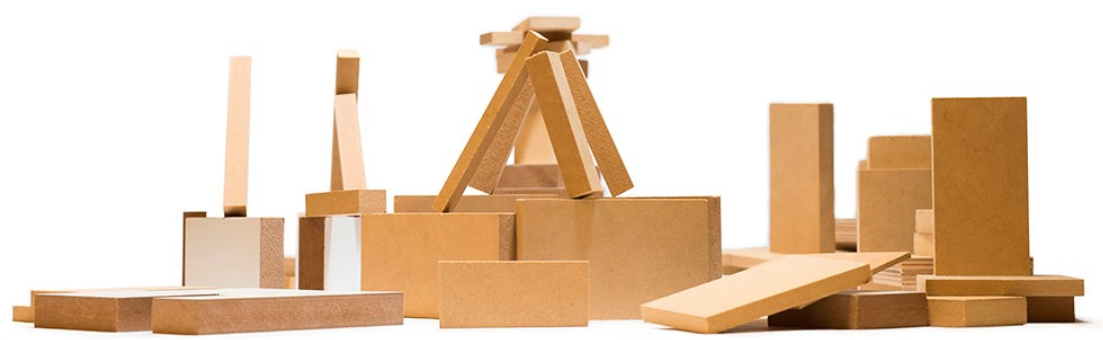

Figura 4. Detalle de representación en madera del lugar docente (metáfora de profesores/as como navegantes) en un sistema de educación superior, 2019. Fotografía de los autores.

Asimismo, el resultado final asociado a la construcción de ambos sistemas externos de representación, fue nutrido no solamente a través del proceso de aprendizaje interactivo, progresivo e incremental anteriormente descripto, sino que también estuvo influenciado por la diversidad de conocimientos, experiencias, áreas de actuación y metas que traían consigo las personas participantes del curso.

\section{La producción de visualidades colectivas como estrategia}

Las narrativas visuales vinculadas a las memorias del currículum fueron el camino de indagación. La incorporación de medios y tecnologías visuales para la representación, constituyó la posibilidad de la evidencia sobre la que reflexionar sobre las prácticas educativas colectivas.

Como sostiene Catherine Hickey-Moody:

El arte socialmente comprometido puede ser un recurso político. Además, es un medio a través del cual la gente joven puede co-crear y comunicar ideas complejas. Puede también hacer visibles cuestiones culturales, vivas, efímeras y se comunica a través de imágenes, íconos, sentimientos, color, texturas y sonidos. (2021, p. 3)

Los recursos aquí utilizados tuvieron que ver con aquellas evidencias 
visuales que no cumplen los regímenes habituales de construcción textual, jerárquica y secuenciada de los textos académicos habitualmente demandados.

Por esto, se promovieron recursos de creación visual que, basados en las artes, tuvieran las suficientes condiciones de acuerdo colectivo y representatividad respecto a las ideas, deseos y afectos que las profesoras y profesores participantes ponían en juego en su producción.

El recurso tiene que ver con "las cartografías visuales como estrategia de pensamiento para explorar las transiciones de los profesores y las experiencias de aprender nómadas" (HERNÁNDEZ, 2018) y con la posibilidad de "pensar lo impensable" (HERNÁNDEZ; RIERA-RETAMERO, 2021).

Estar prácticas muestran los caminos diversos del aprendizaje (Fig. 5), los pequeños pasos en un territorio desconocido, asombroso, y nos permiten

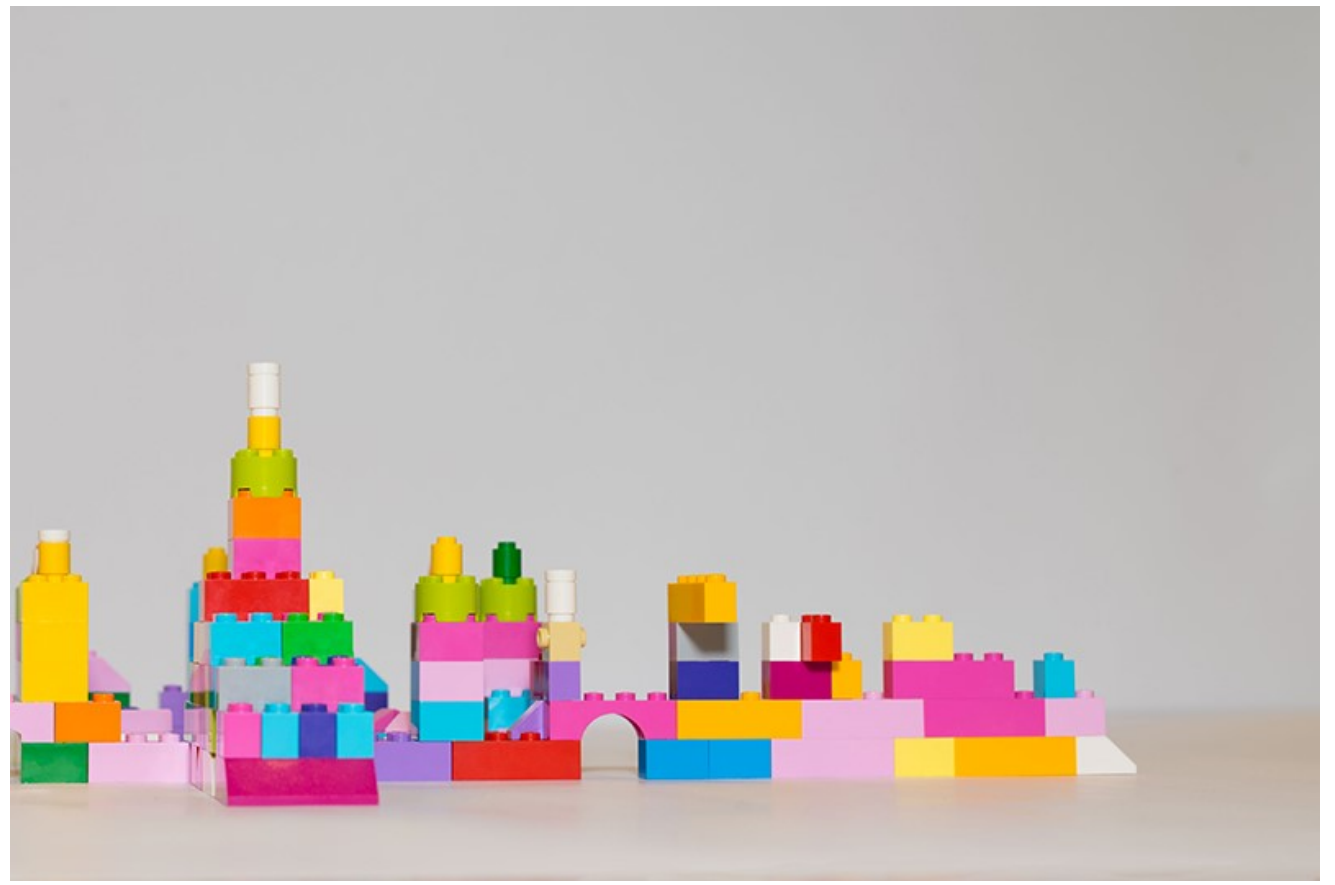

cuestionarnos acerca del tipo de pedagogía que necesitamos (ATKINSON, 2012).

Figura 5. Detalle de representación con bloques plásticos de una trayectoria docente (metáfora como trayectos de puentes y escaleras) en el sistema de educación superior, 2019. Fotografía de los autores.

Nosotros suscribimos la idea de que las pedagogías culturales nos dan la perspectiva necesaria para abordar las producciones visuales de los y las docentes como espacios de acontecimiento y significado.

\section{Conclusiones}

Construir una alternativa de co-docencia con valor para la universidad, especialmente en las disciplinas sociales, humanísticas y artísticas, implica pasar de 
una idea consolidada de contribuir con respuestas para otros a una idea menos segura pero más interesante de formular preguntas con otros.

Aunque las ideas surgieron de procesos de enseñanza precisos, su desarrollo ha desbordado el cometido inicial y podemos afirmar que el proceso de indagación inicial trascendió hacia una formulación pedagógica viable y apreciada por sus participantes.

La modalidad de compartir la docencia universitaria, permitió que los participantes se vieran "en espejo" con la alternativa desarrollada, alcanzando en el ejemplo la posibilidad de poner en contraste sus propias prácticas y experiencias.

La oportunidad de un acción de docencia basada en las artes, en nuestro caso, ha sido útil no sólo para discutir nuestros marcos y referencias como docentes, sino también fomentar el diálogo interdisciplinario de docentes que cursan posgrados.

Un seguimiento de este proyecto implicará profundizar la investigación en formas cualitativas o auto-biográficas, algunas avanzadas en esta experiencia, de manera de observar las proyecciones de este trabajo en las prácticas futuras de los docentes incluidos las experiencias.

\section{Referencias}

ASHBY, Iryna; EXTER, Marisa. "Designing for Interdisciplinarity in Higher Education: Considerations for Instructional Designers" In: TechTrends, n.63, 2019, pp. 202-208.

ATKINSON, Dennis. "Contemporary Art and Art in Education: The New, Emancipation and Truth". In: IJADE, v.31, n.1, 2012, pp. 5-18

BERGER, John. Para entender la fotografía. Barcelona: Gustavo Gilli, 2013.

CALDERÓN, Natalia. Irrumpir lo artístico, perturbar lo pedagógico: La Investigación Artística como espacio social de producción de conocimiento. Tesis (Doctorado en Artes y Educación). Universidad de Barcelona, Barcelona, 2015.

ECHAVARRÍA, Guadalupe. "There is plenty of room at the bottom" In: VERWOERT, Jan; et al. En torno a la investigación artística. Pensar y enseñar arte: entre la práctica y la especulación teórica. Barcelona: MACBA, 2011, pp. 45-58.

FERGUSON, Jacqueline; WILSON, Jenny. "The Co-Teaching Professorship Power And Expertise In The Co-Taught Higher Education Classroom”. In: Scholar-Practitioner Quarterly v.5, n.1, 2011, pp. 52-68.

FONTCUBERTA, Joan. El beso de judas: Fotografía y verdad. Barcelona: Gustavo Gilli, 1997.

GARCÍA HUIDOBRO, Rosario. "Situando el lugar del otro en mi investigación. Trabajar con mujeres chilenas artistas y docentes, como parte de mi propia experiencia". In: Compartir y dialogar en torno a las experiencias del proceso de investigación. Barcelona: AUTODOC, 2013, pp. 26-31.

ouvirouver Uberlândia v. 17 n. 2 p. 284-302 jul.| dez. 2021 
HERNÁNDEZ, Fernando. "La investigación basada en las artes. Propuestas para repensar la investigación en educación”. Educatio Siglo XXI, n.26 . 2008, pp. 85-118.

HERNÁNDEZ, Fernando. "La cultura visual en los procesos de documentación sobre cómo los jóvenes aprenden dentro y fuera de la escuela secundaria." In: Visualidades, Goiânia v.11 n.2, jul-dez., 2013, p. 73-91.

HERNÁNDEZ, Fernando; CALDERÓN Natalia. La investigación artística. Un espacio de conocimiento disruptivo en las artes y en la universidad. Barcelona: Octaedro, 2019

HERNÁNDEZ, Fernando; FENDLER, Rachel. "Explorar los limites: IBA puede ser muchas cosas, pero no cualquier cosa”. In: 2a Conferencia sobre Investigación Basada en las Artes e Investigación Artística de Granada (España), 2014. Disponible en: http://art2investigacion.weebly.com/artiacuteculoscompletos.html Acceso: 14 de mayo de 2021.

HERNÁNDEZ, Fernando; PADILLA-PETRY. "Esbozar el campo de la colaboración en la docencia universitaria”. In HERNÁNDEZ, Fernando; HERRAIZ, Fernando. Compartir docencia en la Universidad. ¿Cómo es que venís juntos a clase?. Barcelona: Octaedro-ICE-UB, 2019, pp. 15-26.

HERNÁNDEZ, Fernando; RIERA-RETAMERO, Marina. "Arts-Based Research as a Place to Inquiring and Thinking the Unthinkable in Academia and Beyond." In: ONSĖS-SEGARRA, Judit; HERNÁNDEZ, Fernando. Educational Research: (Re)connecting Communities. Proceedings of ECER 2020. NW 29. Research on Arts Education. Barcelona: Universidad de Barcelona. Disponible en: http://diposit.ub.edu/dspace/handle/2445/173985 Acceso: 14 de mayo de 2021.

HICKEY-MOODY, Anna Catherine. "Nuevo materialismo, etnografía, y práctica social comprometida: pliegues espacio-tiempo y la agencia de la materia" In: Praxis educativa, v.25, n.1, enero - abril 2021 https://dx.doi.org/10.19137/praxiseducativa-2021-250104

HOWLETT, Kristina; “” In: Journal of International Students v.10, n.2, 2020, pp. 401-419

LOCK, Jennifer. "The Lived Experiences of Instructors Co-teaching in Higher" In: Brock Education Journal, 26(1) 2016, pp. 26-35.

MCLUHAN, Marshall. El medio es el masaje: un inventario de efectos. Buenos Aires: Paidós, 1967.

MERLEAU-PONTY, Maurice. Fenomenología de la percepción. Barcelona: Península, 1945.

(Autoría propia Xx; Yy; Zz) Prácticas de intervención interdisciplinaria en el espacio urbano: Fragmentos, espacios invisibles y cuerpos contemporáneos. Montevideo: IENBA-Udelar, 2016.

MORELOCK, John. "Power, Perceptions, and Relationships: A Model of Co-Teaching in Higher Education”. In: College Teaching, v.65, n.4, 2017, 182-191.

PÉREZ-ECHEVERRÍA, María del Puy; MARTí, Elena; POZO, Juan Ignacio. "Los sistemas externos de representación como herramientas de la mente". In. Cultura y Educación: Culture and Education, v.22, n.2, 2010 pp. 133-147, DOI:10.1174/113564010791304519

ouvirouver Uberlândia v. 17 n. 2 p. 284-302 jul. |dez. 2021 
STEYERL, Hito. Los condenados de la pantalla. Buenos Aires: Caja Negra, 2012.

Recebido em 17/05/2021 - Aprovado em 17/05/2021

Como citar:

MIRANDA, F.; GRAS, N.; MIGNOT, Y. Una experiencia de co-docencia en la universidad basada en la producción de visualidades colectivas. ouvirOUver, v.17, n.2. p. 284-302. jul./dez. 2021. https://doi.org/10.14393/OUV-v17n2a2021-61133 